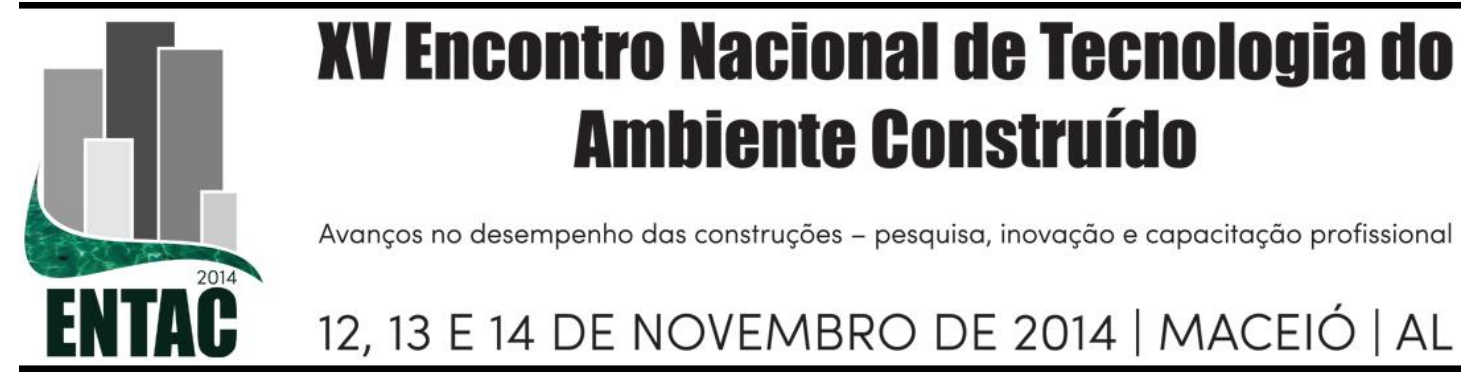

\title{
ANÁLISE DOS MATERIAIS DE EDIFICAÇÕES PARA ILHAS OCEÂNICAS ALICERÇADA EM CONCEITOS SUSTENTÁVEIS
}

\author{
FERRES, Soyana Corrêa (1); DIAS, Bernardo Zandomenico (2); BISSOLI- \\ DALVI, Márcia (3); ALVAREZ, Cristina Engel \\ (1) UFES, (27) 99804-6324, soyanascf@gmail.com (2) UFES, bernardozdias@gmail.com (3) UFES, \\ marciabissoli@gmail.com, UFES (4) UFES, cristinaengel@pq.cnpq.br
}

\begin{abstract}
RESUMO
As edificações construídas em áreas de proteção ambiental e de difícil acesso possuem demandas específicas, principalmente quando se trata dos aspectos relacionados à sustentabilidade. No caso dos materiais de construção, a seleção com base em princípios sustentáveis pode contribuir para o menor impacto possível. Assim, esta pesquisa objetivou analisar os materiais da envoltória de diferentes sistemas construtivos passíveis de serem adotados em edificações projetadas para ilhas oceânicas. Foram analisados os sistemas construtivos concreto-PVC, madeira serrada e madeira plástica. Em relação aos métodos, inicialmente foi feita a pesquisa bibliográfica sendo posteriormente realizada a pesquisa experimental para a análise dos materiais dos sistemas construtivos selecionados através da ferramenta ISMAS - Instrumento para Seleção de Materiais mais Sustentáveis. O ISMAS visa analisar a sustentabilidade dos materiais sob duas temáticas específicas: "economia de matérias primas" e "geração e gestão dos resíduos", cuja aplicação em edifícios projetados para ilhas oceânicas é de fundamental importância. Os resultados demonstraram que o material da envoltória do sistema construtivo em madeira plástica obteve o melhor índice de sustentabilidade (índice Elevado), o que se deve à avaliação positiva em todos os critérios do ISMAS. O teste reforçou o entendimento de que a madeira plástica apresenta potencial de utilização em ilhas oceânicas, principalmente por possuir aspectos como possibilidade de desmontagem, baixa geração de resíduos nas fases de construção, operação e desmonte do edifício e pequena necessidade de manutenção.
\end{abstract}

Palavras-chave: Ilhas oceânicas, Materiais, Sustentabilidade, ISMAS.

\begin{abstract}
The buildings constructed in areas of environmental protection and difficult access have specific demands, especially when it relates to sustainability aspects. In the case of building materials, the selection based on sustainable principles can contribute to minimize impact. Thus, this research aimed to analyze different materials of the envelope that can be adopted in buildings designed for oceanic island construction systems. The PVC-concrete building systems, wood and plastic wood were analyzed. Regarding the methods, initially was done the literature survey and subsequently experimental research for the analysis of materials selected in building systems through ISMAS tool - Tool for Selecting Materials More Sustainable. The ISMAS aims to analyze the sustainability of materials under two specific themes: "economy of raw materials" and "generation and waste management", whose application in buildings designed for oceanic islands is of fundamental importance. The results showed that the material of the envelope of the building system in plastic wood had the best sustainability index (High level), that is attributable to the positive evaluation on all criteria of the ISMAS. The test strengthened the understanding that the plastic wood has potential for use in oceanic islands, specially by having aspects such as the possibility of disassemble, low generation of residues during the construction, operation and disassemble of the building and little maintenance.
\end{abstract}

Keywords: Oceanic Island, Materials, Sustainability, ISMAS. 


\section{INTRODUÇÃO}

As principais condicionantes projetuais para uma edificação a ser instalada em local de interesse ambiental e de difícil acesso como as ilhas oceânicas (Figura 1) estão vinculadas a três temas principais: segurança, logística e meio ambiente, que devem ser consideradas tanto na etapa de construção, como posteriormente, nas atividades de operação, manutenção e eventual desmonte da edificação (ALVAREZ, 2003). Assim, para a construção em ilhas oceânicas - como o Atol das Rocas, o Arquipélago de São Pedro e São Paulo, o Arquipélago de Fernando de Noronha e a Ilha da Trindade (Figura 2) - deve-se ter em vista suas peculiaridades: fragilidade do ambiente; clima quente e úmido; elevada solicitação dos materiais de construção pelas intempéries (altos índices de insolação, calor, umidade e névoa salina, por exemplo); dificuldade de construção e manutenção pela distância do continente e custo das operações; ausência de equipamentos e mão-de-obra especializada tanto na montagem das edificações como em sua posterior operacionalização; e reduzido prazo para execução das obras (ALVAREZ, 2003). Além disso, deve-se levar em conta o âmbito interno da edificação como, por exemplo, a influência dos materiais na qualidade do ar interno do edifício e as trocas térmicas entre o ambiente externo e o interno.

\section{Figura 1 - Esquema dos condicionantes projetuais de edificações para áreas de interesse ambiental e de difícil acesso}

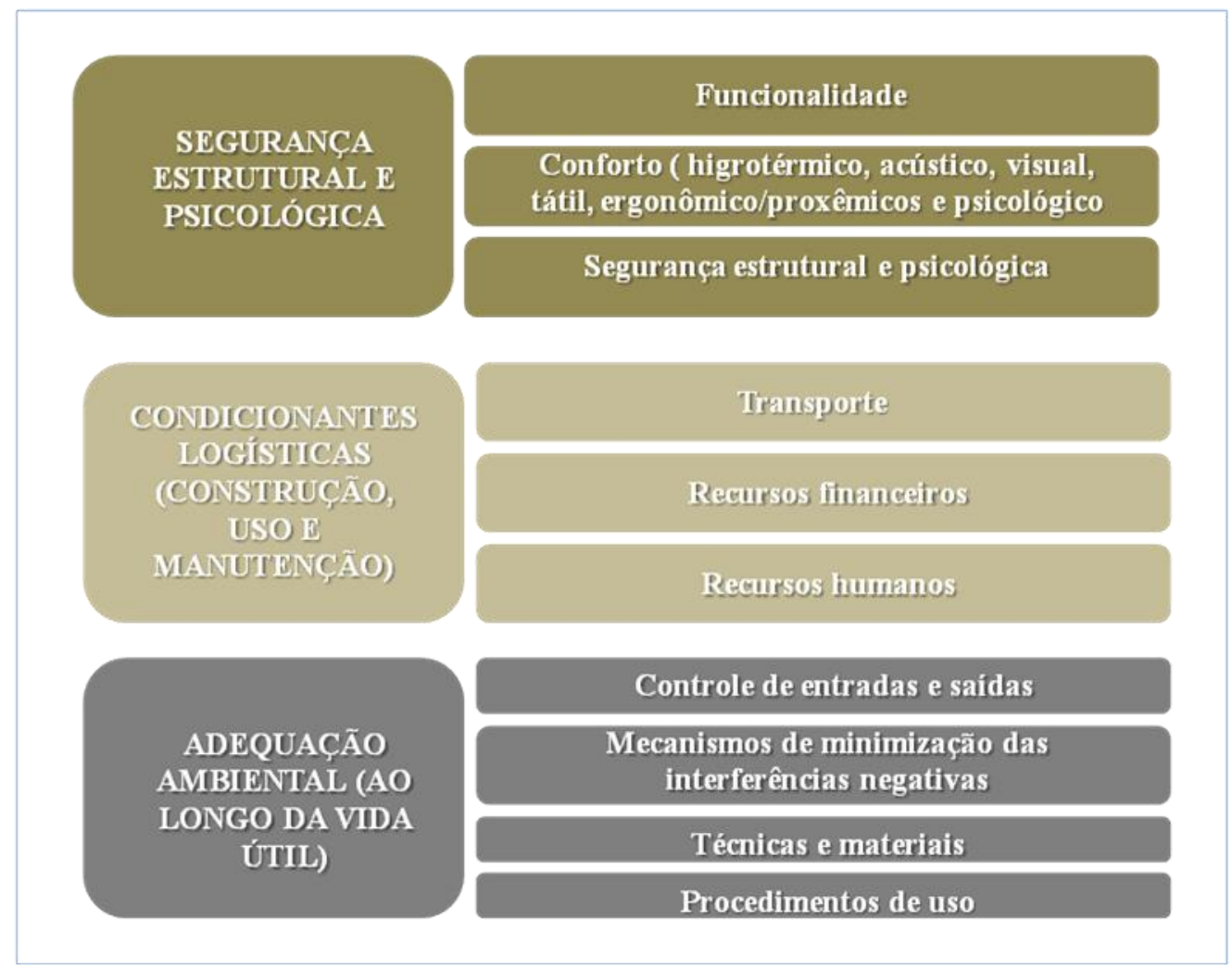

Fonte: Adaptado de Alvarez (2003) 


\section{Figura 2- Localização aproximada das ilhas oceânicas brasileiras e imagens de edificações nesses locais}

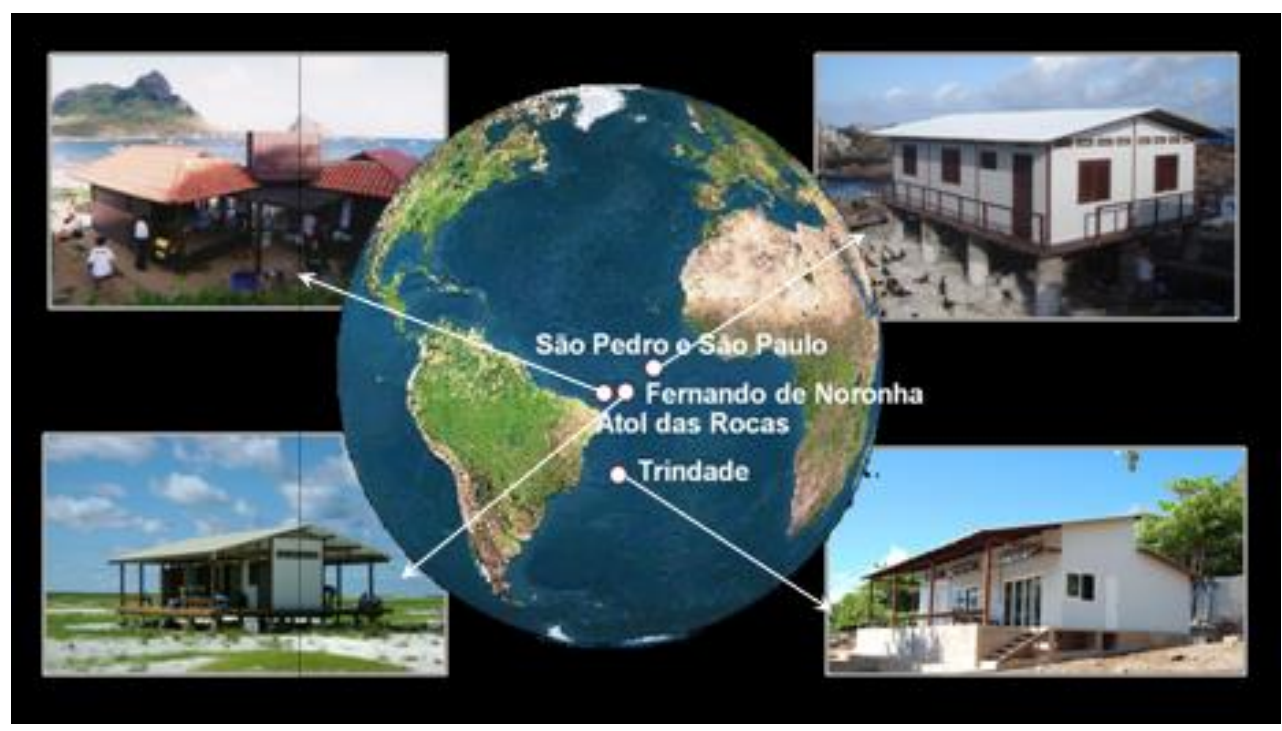

Fonte: Dias e outros (2014)

A adoção dos aspectos relacionados à sustentabilidade durante o processo de especificação dos materiais de construção de um edifício é muito importante para uma edificação que visa o menor impacto ambiental possível (BISSOLI-DALVI, 2014). Assim, esta pesquisa buscou analisar, utilizando o Instrumento para Seleção de Materiais mais Sustentáveis - ISMAS, os aspectos relacionados à sustentabilidade dos materiais presentes nas envoltórias de três sistemas construtivos selecionados: concretoPVC, madeira serrada e madeira plástica.

Ressalta-se que os dois primeiros sistemas já foram aplicados em estações científicas situadas em ilhas oceânicas brasileiras, e o último (madeira plástica) é um sistema construtivo hipotético, cuja avaliação de desempenho em comparação com os demais sistemas construtivos citados tem mostrado ser este um sistema promissor para uma futura estação científica a ser construída no Arquipélago de Fernando de Noronha.

\section{MÉTODO}

De cunho experimental, o estudo contemplou inicialmente a pesquisa bibliográfica a fim de identificar os condicionantes ambientais de áreas inóspitas, particularmente de ilhas oceânicas. Posteriormente foram realizadas entrevistas informais com pesquisadores especializados em construções em áreas inóspitas e levantados, através de pesquisa documental, os sistemas construtivos e os respectivos materiais comumente utilizados em edificações em ilhas oceânicas e outros de possível emprego em novas edificações.

Concomitante à seleção dos sistemas construtivos considerados prioritários para a análise, foram elencadas as possíveis ferramentas de avaliação de sustentabilidade dos materiais, sendo escolhido o Instrumento para a Seleção de Materiais Mais Sustentáveis - ISMAS (BISSOLI-DALVI, 2014), tanto em função da abordagem como pela facilidade de acesso e utilização.

Ressalta-se que o ISMAS tem por objetivo auxiliar o projetista na avaliação da sustentabilidade dos materiais, sendo de manuseio simples, prático e gratuito. $\mathrm{O}$ 
instrumento aborda critérios ambientais que se relacionam com a "economia de matérias primas" e a "geração e gestão dos resíduos" - temas fundamentais quando se trata de edificações projetadas para ilhas oceânicas - e é constituído por sete critérios, sendo que para cada um destes há três níveis de desempenho, estando cada nível vinculado a uma estratégia e a um determinado valor numérico. O desempenho final do material no ISMAS é calculado utilizando-se uma média ponderada, na qual o nível de desempenho alcançado em cada critério é multiplicado por seu respectivo peso. O resultado é dado numa escala que varia entre -1 e 1 , sendo que quanto maior o valor numérico, mais sustentável é o material (Figura 3).

\section{Figura 3 - Escala de desempenho do Índice de Sustentabilidade proposto pelo ISMAS}

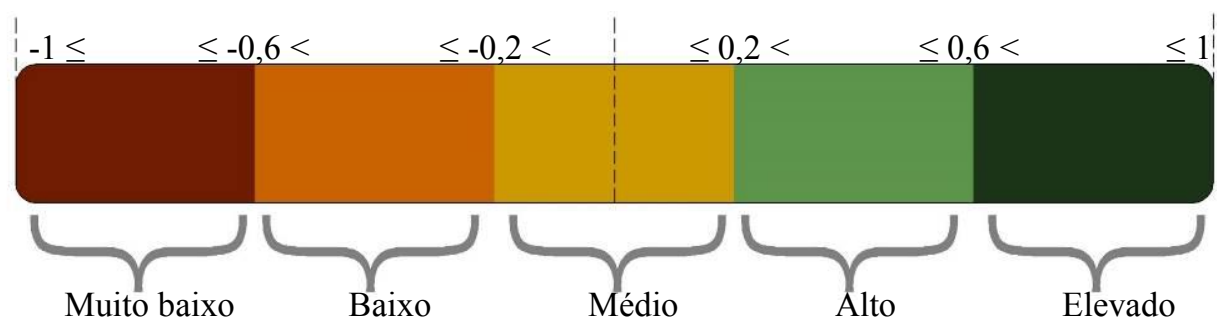

Fonte: Bissoli-Dalvi (2014).

\section{SISTEMAS CONSTRUTIVOS/ MATERIAIS}

Seguem apresentadas as sínteses das características mais relevantes dos sistemas construtivos concreto-PVC, madeira serrada e madeira plástica, selecionados para análise.

\subsection{Concreto-PVC}

O sistema é formado por paredes estruturais constituídas de perfis de PVC preenchidas com concreto moldado in loco (Figura 4). No espaço interno entre os perfis de PVC são posicionadas barras de aço visando reforçar as ligações entre as vedações e aumentar a estabilidade do sistema construtivo após a cura do concreto. Os perfis de PVC são utilizados como fôrmas para o concreto e compõem, juntamente com ele, a parede/estrutura da edificação, tendo também função de revestimento e acabamento final (SISTEMA..., 2013). O sistema construtivo possui como características a facilidade e a rapidez na montagem; a possibilidade de não utilização de equipamentos pesados para a construção; a redução nos custos de construção e manutenção em relação aos demais sistemas analisados; uma relativa segurança contra o fogo; a resistência à ação de fungos e às intempéries; e atende aos requisitos da norma NBR 15575 (SISTEMA..., 2013). Ressalta-se que para questões relacionadas ao conforto térmico e acústico, por exemplo, outras características da edificação são consideradas para verificar se o sistema construtivo cumpre ou não o desempenho determinado pela NBR 15575, ou seja, caso elementos como cobertura ou esquadrias sejam modificados, o resultado pode ser diferente.

Por outro lado, o PVC vem sendo associado a problemas relacionados com a qualidade do ar interno da edificação, uma vez que libera no ambiente substâncias suspeitas de causarem problemas endócrinos em seres humanos (HEUDORF; MERSCHSUNDERMANN; ANGERER, 2007). Outro aspecto do sistema é a liberação de 
compostos altamente tóxicos em caso de queima (WEY et al., 2001), problema que pode ser mitigado com a presença de aberturas que mantenham uma ventilação constante no interior da edificação, permitindo a saída da fumaça tóxica.

Figura 4 - Sistema construtivo concreto-PVC (Ilha da Trindade)

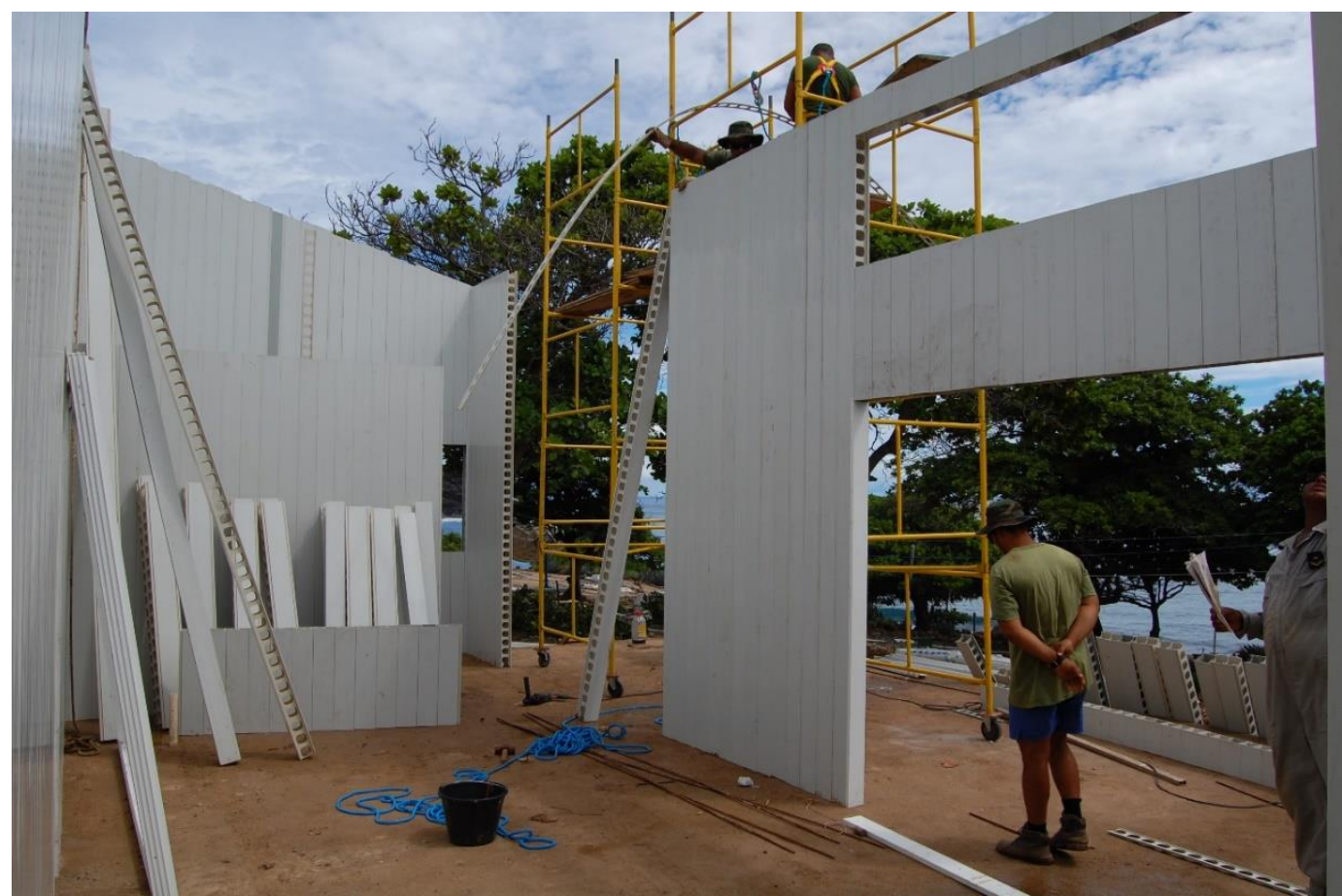

Fonte: Acervo dos autores.

\subsection{Madeira serrada}

As técnicas utilizadas nas ilhas oceânicas a partir da madeira serrada são o denominado sistema "viga-laje em madeira", adotado especialmente para a Estação Científica do Arquipélago de São Pedro e São Paulo (Figura 5) devido a ocorrência de abalos sísmicos no local, e os tradicionais sistemas pré-fabricados adotados para a Estação Científica do Atol das Rocas (Figura 6) e para edificações e instalações de apoio e lazer no Arquipélago de Fernando de Noronha.

Ambos os sistemas em madeira serrada são executados a partir do encaixe e fixação com parafusos ou barras metálicas rosqueadas de peças de madeira pré-fabricadas, tornando o manuseio e a montagem rápidos, além de gerar menor quantidade de resíduos no canteiro de obras. A madeira apresenta propriedades físicas (higrospicidade, flexibilidade e durabilidade) e mecânicas (resistência à compressão, à tração, à flexão e dureza) favoráveis à realidade extrema das ilhas oceânicas (DIAS et al., 2014). Destacase nos estudos sobre sustentabilidade por ser um recurso renovável, no entanto, requer constante atividade de manutenção, seja para a proteção do material e/ou ampliação da vida útil da edificação, seja para a garantia da habitabilidade dos ambientes internos, principalmente considerando os altos níveis de umidade e insolação existentes nas ilhas oceânicas. 
Figura 5 - Sistema construtivo viga-laje em madeira (Arquipélago de São Pedro e São Paulo)
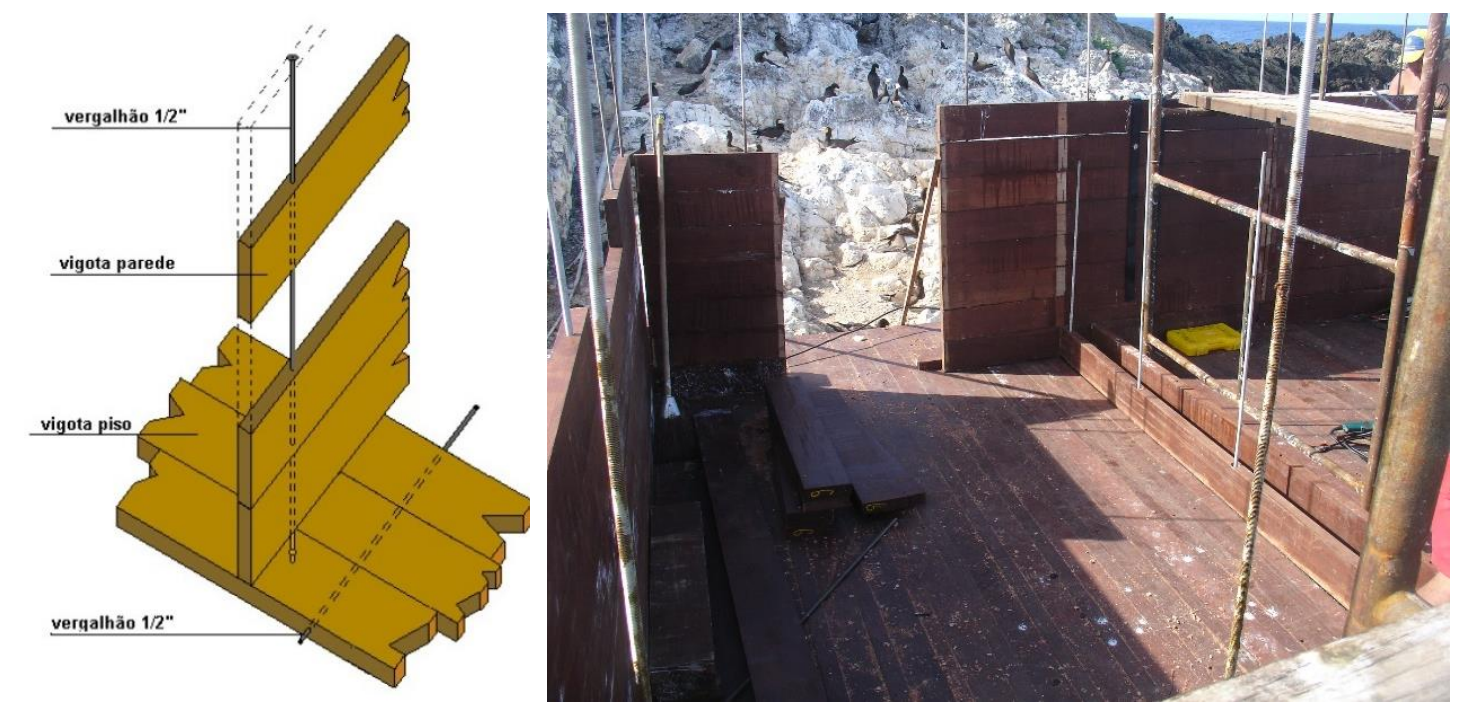

Fonte: Figura à esquerda, Alvarez (2003); figura à direita, acervo dos autores.

Figura 6 - Sistema construtivo pré-fabricado em madeira (Atol das Rocas)

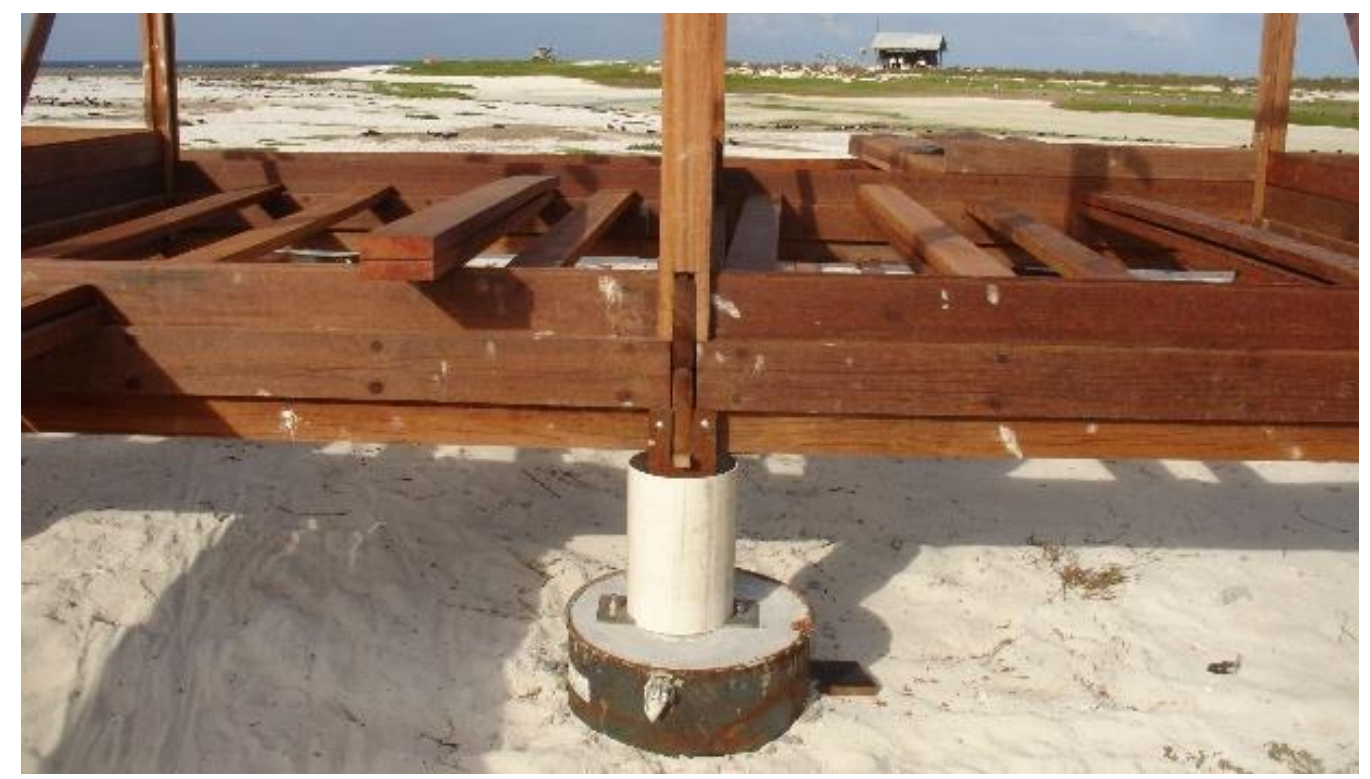

Fonte: Acervo dos autores.

\subsection{Madeira plástica}

Ainda em fase de desenvolvimento, o sistema construtivo está sendo projetado com técnica semelhante ao sistema viga-laje em madeira, sendo somente substituída a madeira serrada pela madeira plástica. Isso a princípio é possível, visto que a madeira plástica pode ser aparafusada e manuseada com equipamentos similares aos utilizados em madeira serrada (CALKINS, 2009).

A madeira plástica é fabricada a partir de resíduos plásticos, minerais e/ou vegetais, como a cinza volante, a farinha de madeira e a serragem, por exemplo, provenientes da queima de carvão e da indústria madeireira e moveleira, respectivamente (Figura 7). Apesar de incluir resíduos vegetais em sua composição, a madeira plástica apresenta 
resistência à atuação de cupins, uma vez que os resíduos vegetais, em grande parte, ficam envoltos pelo plástico, entretanto, dependendo da quantidade empregada, as peças de madeira plástica podem sofrer inchamento e deformações quando em contato prolongado com água e descolorir mais rapidamente (KLYOSOV, 2007). Além disso, se iniciado o processo de oxidação da matriz polimérica - processo danoso ao material e que pode culminar com a perda de resistência mecânica e até com a ruptura da peça - os raios solares e a água podem contribui para sua aceleração.

As pesquisas têm apontado a madeira plástica como um material promissor para uso em novas estações científicas, embora atualmente a aplicação desta técnica se encontre em fase incipiente na construção de edificações (DIAS et al., 2014). Sua principal vantagem em relação à madeira serrada é sua reduzida necessidade de manutenção e, com isso, diminuição dos custos com mão de obra e com emprego de novos materiais, não precisando ser envernizada ou receber acabamento superficial (CALKINS, 2009).

\section{Figura 7 - Exemplo de sistema construtivo em madeira plástica}
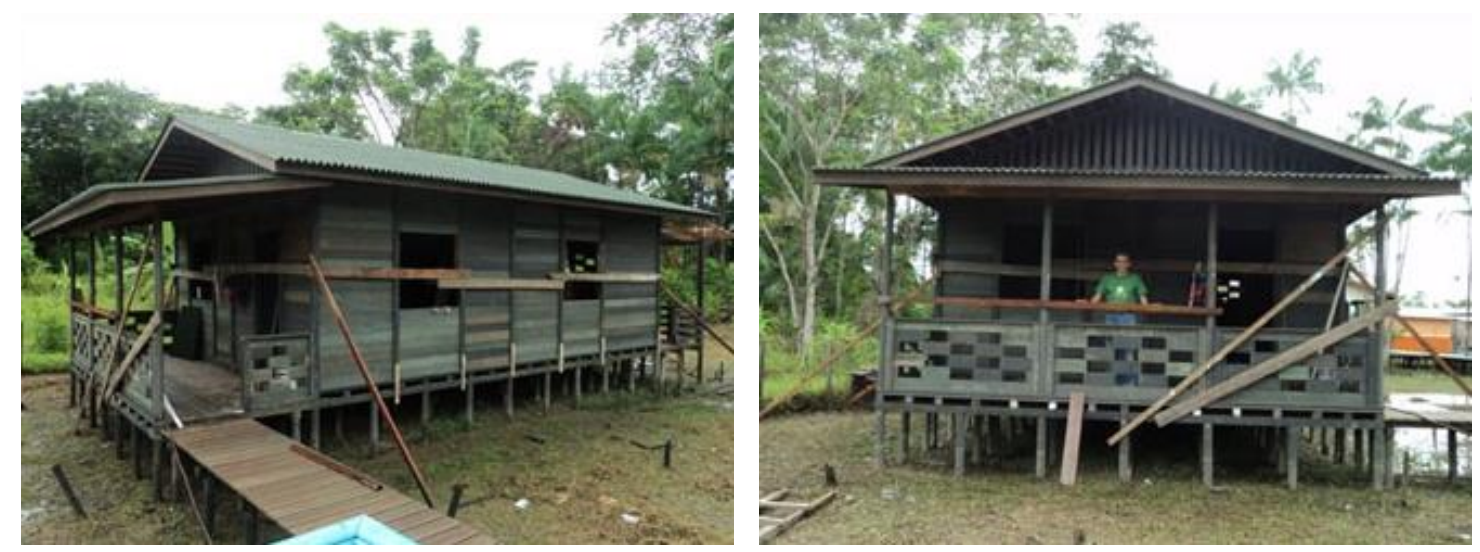

Fonte: Casa..., acesso em 10 maio 2014.

\section{RESULTADOS E DISCUSSÕES}

Os resultados dos testes, utilizando-se o ISMAS, dos materiais presentes na envoltória dos sistemas construtivos selecionados seguem expostos na Erro! Autoreferência de indicador não válida., sendo possível visualizar o desempenho de cada um deles em cada critério de avaliação do instrumento.

Tabela 1 - Aplicação do ISMAS aos materiais

\begin{tabular}{|c|c|c|c|c|c|c|}
\hline Critério & \& & $\stackrel{\circlearrowright}{\frac{1}{Z}}$ & $\sum_{2}^{u}$ & 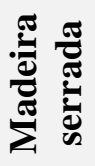 & 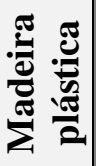 & Marcas de referência \\
\hline \multirow{3}{*}{$\begin{array}{l}\text { 1. É possível ser } \\
\text { reaproveitado, no } \\
\text { todo ou em parte }\end{array}$} & \multirow{3}{*}{1} & +1 & & & & $\begin{array}{l}\text { É possível ser reaproveitado com mínimo } \\
\text { processamento ou de forma direta, sem } \\
\text { processamento }\end{array}$ \\
\hline & & 0 & & & & $\begin{array}{l}\text { É possível ser reaproveitado, contudo } \\
\text { requer processamento industrial }\end{array}$ \\
\hline & & -1 & & & & $\begin{array}{l}\text { Não atendimento ao requisito mínimo } \\
\text { estabelecido para o nível } 0\end{array}$ \\
\hline
\end{tabular}




\begin{tabular}{|c|c|c|c|c|c|}
\hline Critério & $\stackrel{0}{0}$ & $\overline{\vec{d}}$ & U & 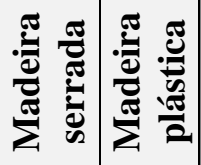 & Marcas de referência \\
\hline \multirow{3}{*}{ 2. É renovável } & \multirow{3}{*}{4} & +1 & & & $\begin{array}{l}\text { Todo o material é de fonte renovável ou } \\
\text { constituído por matérias primas } \\
\text { abundantes }\end{array}$ \\
\hline & & 0 & & & $\begin{array}{l}\text { Aproximadamente a metade dos } \\
\text { elementos que compõem o material é de } \\
\text { fonte renovável ou matérias primas } \\
\text { abundantes }\end{array}$ \\
\hline & & -1 & & & $\begin{array}{l}\text { Os elementos que constituem o material } \\
\text { e que são de fonte renovável ou } \\
\text { abundantes estão presentes em } \\
\text { quantidades mínimas }\end{array}$ \\
\hline \multirow{3}{*}{$\begin{array}{l}\text { 3. Dispensa } \\
\text { materiais } \\
\text { adicionais para } \\
\text { acabamento }\end{array}$} & \multirow{3}{*}{0,5} & +1 & & & $\begin{array}{l}\text { Não necessita de materiais adicionais } \\
\text { para acabamento superficial }\end{array}$ \\
\hline & & 0 & & & $\begin{array}{l}\text { Necessita de materiais de acabamento } \\
\text { superficial, contudo este é considerado } \\
\text { apenas um material de proteção }\end{array}$ \\
\hline & & -1 & & & $\begin{array}{l}\text { Não atendimento ao requisito mínimo } \\
\text { estabelecido para o nível } 0\end{array}$ \\
\hline \multirow{3}{*}{$\begin{array}{l}\text { 4. Possui } \\
\text { elementos } \\
\text { reciclados }\end{array}$} & \multirow{3}{*}{2} & +1 & & & $\begin{array}{l}\text { Possui elementos reciclados em sua } \\
\text { composição oriundos de outros materiais }\end{array}$ \\
\hline & & 0 & & & $\begin{array}{l}\text { Possui elementos reciclados em sua } \\
\text { composição oriundos do mesmo material }\end{array}$ \\
\hline & & -1 & & & $\begin{array}{l}\text { Não possui elementos reciclados em sua } \\
\text { composição }\end{array}$ \\
\hline \multirow{3}{*}{$\begin{array}{l}\text { 5. A } \\
\text { durabilidade } \\
\text { independe de } \\
\text { manutenção }\end{array}$} & \multirow{3}{*}{1} & +1 & & & $\begin{array}{l}\text { Possui VUP mínima estabelecida pela } \\
\text { NBR } 15575 \text {, e a manutenção ocorre } \\
\text { somente com limpeza }\end{array}$ \\
\hline & & 0 & & & $\begin{array}{l}\text { Possui vida útil de projeto (VUP) mínima } \\
\text { estabelecida pela NBR } 15575 \text {, e exige } \\
\text { manutenções periódicas com o uso de } \\
\text { novos materiais }\end{array}$ \\
\hline & & -1 & & & $\begin{array}{l}\text { Não atendimento ao requisito mínimo } \\
\text { estabelecido para o nível } 0\end{array}$ \\
\hline \multirow{3}{*}{$\begin{array}{l}\text { 6. Favorece a } \\
\text { desmontagem } \\
\text { visando o } \\
\text { reaproveitamento }\end{array}$} & \multirow{3}{*}{0,5} & +1 & & & $\begin{array}{l}\text { É possível ser facilmente separado dos } \\
\text { demais materiais por usar encaixes } \\
\text { mecânicos como amarrações, parafusos, } \\
\text { etc. }\end{array}$ \\
\hline & & 0 & & & $\begin{array}{l}\text { É possível ser separado dos demais } \\
\text { materiais construtivos, contudo podem } \\
\text { ocorrer perdas do material, pois utiliza } \\
\text { ligantes, colas ou aglomerantes }\end{array}$ \\
\hline & & -1 & & & $\begin{array}{l}\text { Não atendimento aos requisitos mínimos } \\
\text { estabelecidos para o nível } 0\end{array}$ \\
\hline
\end{tabular}




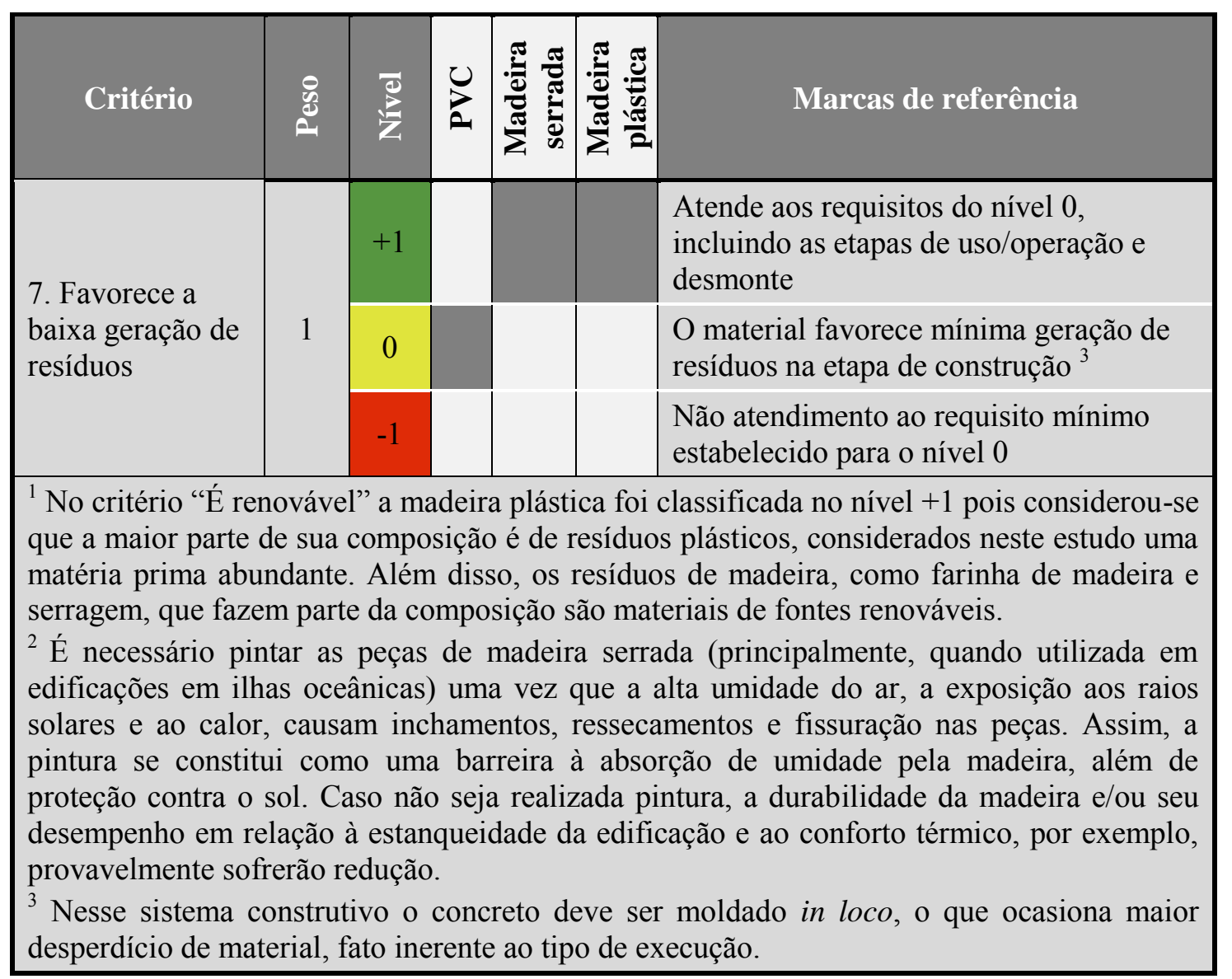

Fonte: Adaptado de Bissoli-Dalvi (2014)

O desempenho da madeira serrada no teste foi superior ao do PVC, que obteve nota 0,10 (índice Médio), mas foi inferior ao desempenho da madeira plástica, obtendo nota 0,35 (índice Alto). Dessa forma, a madeira serrada, apesar de possuir pontos positivos como ser reaproveitável, renovável, desmontável e gerar poucos resíduos durante a construção, uso e desmonte da edificação, tem como pontos desfavoráveis não apresentar material reciclado em sua composição, além de necessitar de material de acabamento e constante manutenção (tendo em vista as características de uma ilha oceânica), acarretando custos econômicos e ambientais. Já o material PVC apresentou apenas dois critérios com respostas positivas. Além disso, não pode ser desmontado uma vez que no sistema construtivo para o qual está sendo considerado, os perfis de PVC e o concreto existente em seu interior se tornam um elemento inseparável, restando apenas a demolição. Vale ressaltar que o critério "É renovável" é o de maior peso, sendo o nível de desempenho alcançado nele um fator preponderante no resultado final.

Já a madeira plástica obteve o melhor índice de sustentabilidade (índice Elevado), mantendo o nível +1 em todos os critérios de avaliação. Isso se deve a possibilidade de modulação de suas peças, de realização de encaixes e de fixação por parafusos e pregos e, com isso, reduzir a perda de material e a geração de resíduos durante a construção, manutenção e desmonte da edificação. Além disso, sua fabricação a partir de resíduos estimula a reciclagem e contribui para a diminuição de áreas de descarte de lixo. 


\section{CONSIDERAÇÕES FINAIS}

O teste realizado demonstrou que além de apresentar maior durabilidade e baixa necessidade de manutenção quando comparada à madeira serrada, fatores determinantes para construções em ilhas oceânicas, a madeira plástica também desponta em relação a questões ambientais.

Deve ser enfatizado que o desempenho máximo atingido pela madeira plástica no ISMAS não significa ser ela um material sustentável, uma vez que nenhum é, mas sim, reflete o bom desempenho de suas características frente às temáticas abordadas pelo instrumento, isto é, "economia de matérias primas" e "geração e gestão de resíduos" que, por sua vez, são temáticas cruciais para edificações projetadas para ambientes frágeis como as ilhas oceânicas.

\section{AGRADECIMENTOS}

Os autores agradecem à Coordenação de Aperfeiçoamento de Pessoal de Nível Superior (CAPES) e à Fundação de Amparo à Pesquisa do Espírito Santo (FAPES).

\section{REFERÊNCIAS}

ALVAREZ, C. E. Metodologia para construção em áreas de difícil acesso e de interesse ambiental: aplicabilidade na Antártica e nas ilhas oceânicas brasileiras. 2003. 192 f. Tese (Doutorado em Arquitetura e Urbanismo). Faculdade de Arquitetura da Universidade de São Paulo. São Paulo, 2003.

BISSOLI-DALVI, M. ISMAS: a sustentabilidade como premissa para a seleção de materiais. 2014. 194 f. Tese (Doutorado em Arquitetura e Urbanismo). Facultad de Arquitectura, Construcción y Diseño. UniversidaddelBío-Bío, Concepción, 2014.

CALKINS, M. Materials for Sustainable Sites: a complete guide to the evaluation, selection, and use of sustainable construction materials. Hoboken: John Wiley\& Sons, Inc., 2009.

Casa de Plástico na Ilha de Marajó. Disponível em: $<$ http://marcasitehost.com.br/romanplast/?page_id=7>. Acesso em: 10 maio 2014.

DIAS, B. Z.; FUKAI, F. M.; DORIO, N.; ALVAREZ, C. E. Concreto-PVC, madeira serrada e madeira plástica: estudo comparativo de adequabilidade para construções em ilhas oceânicas. In: I Congresso Luso-Brasileiro de Materiais de Construção Sustentáveis. Minho. Anais.., 2014.

HEUDORF, U.; MERSCH-SUNDERMANN, V.; ANGERER, J. Phthalates: toxicology and exposure. International Journal of Hygiene and Environmental Health, v. 210, n. 5, p. 623 34, out. 2007.

KLYOSOV, A. A. Wood-Plastic Composites. Hoboken: John Wiley \& Sons, Inc., 2007.

SISTEMA NACIONAL DE AVALIAÇÕES TÉCNICAS. DATec n0 017: Sistema Construtivo Global de paredes constituídas por painéis de PVC preenchidos com concreto. Brasília, 2013.

WEY, M. Y.; OU, W. Y.; LIU, Z. S.; TSENG, H. H.; YANG, W. Y.; CHIANG, B. C. Pollutants in incineration flue gas. Journal of Hazardous Materials, v. 82, n. 3, p. 247-62,abr. 2001. 